\title{
PEMBUATAN DAN KARAKTERISTIK RESIN MELAMIN FORMALDEHID SEBAGAI BAHAN COATING
}

\section{CHARACTERISTICS AND MANUFACTURINGS OF MELAMINE FORMALDEHYDE RESIN AS COATING MATERIALS}

\author{
Fauziati, Ageng Priatni \\ Balai Riset dan Standardisasi Industri Samarinda \\ JI. Harmonika No.3 Samarinda 75123 \\ Email : brisi_sam@yahoo.com
}

Naskah diterima 13 Juni 2011, disetujui 15 Nopember 2011

\begin{abstract}
ABSTRAK
Penelitian ini bertujuan membuat Resin Melamin Formaldehid sebagai bahan baku coating dengan mol ratio yang bervariasi serta mengetahui karakteristik resin MF. Penelitian ini dilakukan dengan cara mereaksikan Melamin dan Formaldehida dengan perbandingan mol 1:2; $1: 3 ; 1: 4 ; 1: 5$ dan $1: 6$ dan mencatat waktu reaksinya kemudian mengkarakteristik sifat-sifat resin MF yang dihasilkan dengan parameter Viscositas, Pot Life serta $\mathrm{pH}$. Dari hasil penelitian ini diperoleh kesimpulan bahwa Resin Melamin Formaldehida yang terbaik dihasilkan pada perbandingan mol Melamin:Formaldehida 1:6 dengan waktu reaksi 14 menit dan karakteristik sebagai berikut: nilai viskositas 1.550 $\left(\mathrm{mm}^{2} / \mathrm{s}\right) /$ centi stokes; Pot Life 3 hari dan $\mathrm{pH}$ 6,63.
\end{abstract}

Kata kunci : coating, formaldehida, melamin, resin, viscositas.

\begin{abstract}
This research aims to manufacture Melamine Formaldehyde Resin as a raw material coating with a mole ratio that is different and knowing the characteristics of MF resins. The research was carried out by reacting Melamine and Formaldehyde with a mole ratio of 1:2; $1: 3 ; 1: 4 ; 1: 5$ and 1:6 and characterize the properties of the resulting Melamine Formaldehyde Resin with Viscosity, Pot Life and $\mathrm{pH}$ parameter. The conclusion of this research that the best Melamine Formaldehyde Resin is produced on a mole ratio 1:6 of Melamine Formaldehyde with a reaction time of 14 minutes and the following characteristics : viscosity value is $1550\left(\mathrm{~mm}^{2} / \mathrm{s}\right) /$ centistokes; Pot Life is 3 days and the $\mathrm{pH}$ is 6,63.
\end{abstract}

Keywords : coating, formaldehyde, melamine, resin, viscosity.

\section{PENDAHULUAN}

$\mathrm{S}$ eiring dengan perkembangan jaman, kebutuhan masyarakat akan meubel senantiasa meningkat baik dari segi kualitas maupun kuantitasnya. Perkembangan industri meubel tidak terlepas dari penggunaan bahan coating di dalam proses finishing atau pekerjaan akhir. Bahan coating yang banyak digunakan 
industri meubel, baik home industri maupun industri skala besar, merupakan bahan coating sintetis dan bahan siap pakai yang banyak dijual dipasaran dengan berbagai merek. Salah satu jenis coating yang ada dipasaran adalah merek IMPRA yang merupakan bahan coating dengan bahan dasar melamin.

Bahan coating sintesis dapat dibuat dengan berbagai formulasi diantaranya dengan mereaksikan melamin dengan formaldehid menghasilkan resin melamin. Melamin (2,4,6-Triamino-s-triazin) adalah produk polimerisasi trimer dari cyanamid yang merupakan ikatan yang secara termo dan kimia sangat tahan terhadap panas, yang akan meleleh dan menyublim pada suhu $354{ }^{\circ} \mathrm{C}$ dengan air, basa atau asam. Secara teknis pembuatan melamin dari cyanamid (monomers) melalui pembentukan dicyandiamid (dimer) menjadi Melamin (trimer). Melamin dengan berat molekul (BM) 126,3 merupakan suatu zat yang berbentuk serbuk kristal berwarna putih; memiliki kelarutan yang kurang dalam air yang pada suhu $20^{\circ} \mathrm{C}$ hanya $0,32 \mathrm{~g}$, sedangkan pada suhu $100{ }^{\circ} \mathrm{C}$ dapat larut hingga 5,05 g/100 ml. Kelarutannya yang tinggi dalam air panas, digunakan sebagai bahan baku teknis (Baumann, 1967; Rosamah, 2004). Melamin yang paling banyak digunakan merupakan hasil kondensasi dengan formaldehida, yang biasa disebut dengan aminoplast (Habenich, 1977). Formadehid merupakan aldehida sederhana, yaitu suatu senyawa yang sangat reaktif, sehingga merupakan bahan kimia dengan unsur karbon yang penting. Formaldehid juga bisa bereaksi dengan sendirinya membentuk oligomer atau polimer, yang dengan adanya penambahan sedikit asam atau basa akan memberikan pengaruh katalisasi yang kuat. Pembuatan formaldehid secara teknis melalui dehidrogenasi dari methanol dengan adanya unsur perak atau melalui oksidasi udara dengan adanya kontak dari mobildenoksida (Roffael, 1975).

Resin melamin formaldehid merupakan suatu resin amino yang diperoleh dari proses polimerisasi formaldehid dengan melamin. Pembuatan resin amino dapat dilakukan baik dalam suasana asam maupun basa. Prepolimernya dapat dibuat pada kondisi $\mathrm{pH}$ yang bervariasi, tergantung pada suhu reaksi yang dipilih. Polimerisasi berhenti dengan proses pendinginan dan akan membawa $\mathrm{pH}$ mendekati netral. Untuk penggunaannya sebagai perekat,diperoleh dengan mereaksikan $1 \mathrm{~mol}$ melamin dengan 2 hingga $3 \mathrm{~mol}$ formaldehyde yang akan membentuk ikatan metilol. Dalam beberapa reaksi melamin direaksikan dengan formaldehid hingga rasio 1:6. Pembuatan resin melamin biasanya menggunakan suhu tertentu. Resin melamin memiliki kombinasi kecerahan dan tidak berwarna dibanding resin yang lain seperti fenolik dan memiliki sifat superior dalam kekerasan dan tahan terhadap panas dan kelembaban dibanding resin urea sehingga sesuai digunakan sebagai coating.

Secara teknis pemanfaatan hasil reaksi antara formaldehid dengan melamin, paling utama dalam bidang pengerjaan kayu (sebagai lem kayu, yang mengalami proses tekanan). Pemanfaatan lain dalam bidang pembuatan kertas, sebagai bahan tambahan dalam industri tekstil (sebagai bahan anti kusut) dan dalam bidang penyamakan kulit. Pemanfaatan penting aminoplast dalam bidang lack dan coating (pelapisan) menjadi lebih luas dengan adanya kemungkinan kombinasi 
dengan alkid resin, polyester dan epoksi resin dalam menghasilkan produk coating yang lebih baik.

Di Kalimantan Timur, khususnya di kota Bontang terdapat PT. DSM Kaltim Melamin yaitu satu-satunya penghasil Melamin di Kaltim dan salah satu terbesar di Indonesia. PT. DSM Kaltim Melamin beroperasi sejak tahun 1997 sampai sekarang. Semua produk Melamin yang dihasilkan diekspor ke Asia Pasifik. Mengingat semakin berkurangnya industri kayu lapis yang ada di Kalimantan Timur disebabkan oleh berkurangnya bahan baku, serta tersedianya bahan Melamin di Kaltim yang selama ini belum dimanfaatkan oleh industri lokal maka pengembangan resin Melamin formaldehid perlu dikembangkan untuk keperluan produk lain seperti coating mebel.

\section{BAHAN DAN METODA}

\section{Bahan dan Peralatan}

Bahan yang digunakan pada penelitian ini adalah Melamin dan Formaldehid $37 \%$ yang diperoleh dari PT. DSM Kaltim, Vernish kayu komersial (merk impra), thinner dan hardener diperoleh dari industry perekat yang ada di Samarinda.

Peralatan yang digunakan adalah $\mathrm{pH}$ meter, Viskometer dan Reaktor yang terdiri dari Labu leher tiga, Heating mantel, Agitator, thermometer dan statif sebagaimana pada gambar 1 .

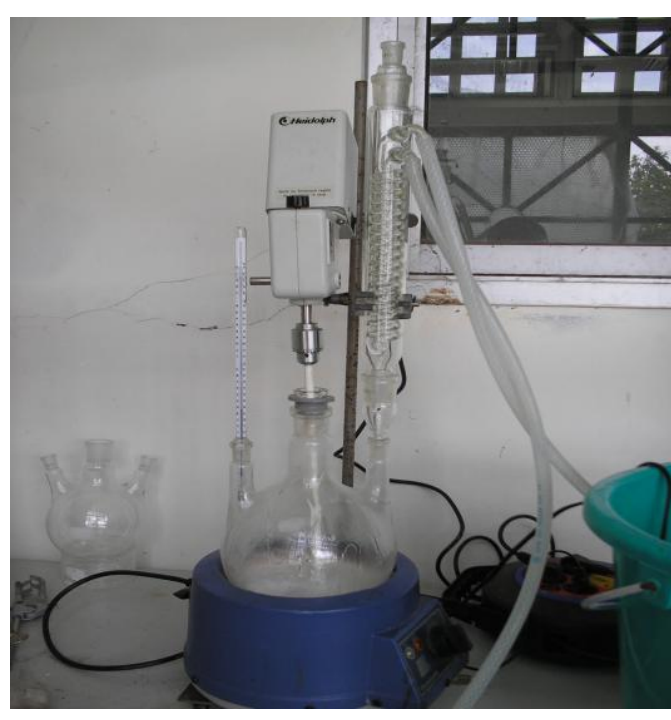

Gambar 1. Reaktor Pembuatan Resin Melamin Formaldehida (MF)

\section{Metode}

\section{Pembuatan Resin MF}

Resin Melamin Formaldehid (resin MF) dibuat dengan mereaksikan $1 \mathrm{~mol}$ melamin $(31,5 \mathrm{~g})$ dengan $2 \mathrm{~mol}$ formaldehid $(40,54 \mathrm{~g})$ di dalam reaktor pada temperatur $90-95{ }^{\circ} \mathrm{C}$ sambil diaduk hingga terbentuk Resin berwarna bening (transparan) dengan mencatat waktu reaksi yang diperlukan. Reaksi juga dilakukan untuk perbandingan mol MF $1: 3 ; 1: 4 ; 1: 5$ dan 1:6. Sebagaimana dapat dilihat pada tabel berikut :

Tabel 1. Komposisi Resin MF 1:2 s/d 1:6

\begin{tabular}{ccc}
\hline $\begin{array}{c}\text { Rasio } \\
(\mathrm{M}: \mathrm{F})\end{array}$ & $\begin{array}{c}\text { Melamin } \\
(\mathrm{g})\end{array}$ & $\begin{array}{c}\text { Formaldehid } \\
37 \%(\mathrm{~g})\end{array}$ \\
\hline $1: 2$ & 31,5 & 40,54 \\
$1: 3$ & 31,5 & 60,81 \\
$1: 4$ & 31,5 & 81,08 \\
$1: 5$ & 31,5 & 101,35 \\
$1: 6$ & 31,5 & 121,0 \\
\hline
\end{tabular}


Pengujian sifat fisis-kimia Resin MF

Pengujian sifat fisis-kimia Resin

MF hasil penelitian ini mengacu pada Standardisasi Nasional Indonesia (SNI, 1998) terdiri atas kenampakan (uji visual) yaitu dengan cara menuangkan sedikit contoh di atas kaca objek, lalu dilaburkan hingga membentuk lapisan film yang tipis. Pengamatan dilakukan secara visual terhadap adanya butiran padat, artikel kasar, dan benda asing lainnya dengan membedakan gelembung udara yang mungkin terbentuk; viskositasnya dengan cara memasukkan sejumlah resin ke dalam bejana viskotester ,kemudian diukur viskositanya dengan viskometer,dalam satuan $\left(\mathrm{mm}^{2} / \mathrm{s}\right) / \mathrm{cst}$; keasaman $(\mathrm{pH})$ resin diukur dengan menggunakan $\mathrm{pH}$ meter. Contoh dimasukkan ke dalam gelas piala $100 \mathrm{ml}$, kemudian diukur $\mathrm{pH}$ - nya sebanyak 3 kali. Nilai $\mathrm{pH}$ merupakan rata-rata hasil pengukuran; Waktu tergelatin mewakili pot life resin sehingga Potlife diukur dengan menghitung lamanya waktu resin membentuk gelatin dalam satuan menit. Sebagai pembading digunakan Coating (Vernish) kayu komersial (merk impra).

\section{HASIL DAN PEMBAHASAN}

\section{Pembuatan Resin MF}

Berdasarkan hasil reaksi antara Melamin $\left(\mathrm{C}_{3} \mathrm{~N}_{6} \mathrm{H} 6\right)$ dan Formaldehid $\left(\mathrm{H}_{2} \mathrm{CO}\right)$ diperoleh resin MF dengan sifat fisis berupa cairan bening dan berbau khas fenol untuk perbandingan mol 1:2 s/d 1:6 pada suhu $90-95{ }^{\circ} \mathrm{C}$ dan potlife sebagaimana dapat dilihat pada Tabel 2 :

Tabel 2. Kenampakan dan Potlife Resin MF pada perbandingan mol 1:2 s/d 1:6

\begin{tabular}{ccccc}
\hline Rasio (M:F) & Melamin (g) & $\begin{array}{c}\text { Formaldehid 37\% } \\
(\mathrm{g})\end{array}$ & $\begin{array}{c}\text { Potlife } \\
(\min )\end{array}$ & Kenampakan \\
\hline $1: 2$ & 31,5 & 40,54 & 10 & + \\
$1: 3$ & 31,5 & 60,81 & 11 & + \\
$1: 4$ & 31,5 & 81,08 & 13 & + \\
$1: 5$ & 31,5 & 101,35 & 13 & + \\
$1: 6$ & 31,5 & 121,0 & 14 & + \\
\hline
\end{tabular}

Keterangan (Remarks) : ( + ) Cairan, berwarna bening, berbau khas

Pada tabel 2 dapat dilihat bahwa produk resin MF (Melamin Formaldehid) yang dihasilkan dengan perbandingan mol 1:2 sampai dengan 1:6 hasilnya baik. Melamin mengalami reaksi-reaksi kondensasi dengan formaldehid, dimana dalam adisi nukleofilik awal ke formaldehida, masing-masing gugus

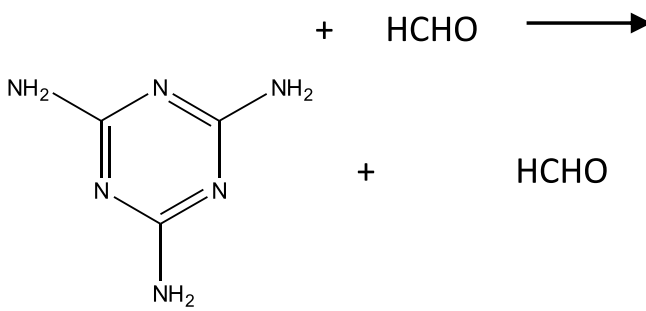

Melamin amino bisa membentuk suatu turunan dimetilol. Melamin dapat bereaksi dengan formaldehid, dengan menghasilkan produk mono- hingga hexametilolmelamin seperti terlihat pada Gambar 2.<smiles>Nc1nc(N)nc(NCO)n1</smiles>

Hexametilolmelamin

Gambar2. Reaksi Melamin dengan Formaldehida 
Resin amino merupakan produk yang dapat dihasilkan dari reaksi antara senyawa karbonil, khususnya aldehida dengan senyawa yang memiliki ikatan gugus $\mathrm{NH}$. Reaksi yang paling terkenal dan penting adalah reaksi antara formaldehida dengan urea dan melamin. Rangkaian keseluruhan dari<smiles>Nc1nc(N)nc(N)n1</smiles>

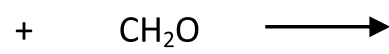

Gambar 3. Reaksi Melamin dengan Formladehid

Seperti halnya urea, melamin beraksi dengan formaldehid membentuk ikatan metilol, memungkinkan terjadinya reaksi hingga 6 (enam) mol formaldehid per mol melamin . Reaksi melamin dengan formaldehid berlansung dibawah kondisi yang serupa dengan resin urea formaldehid hanya pada melamin-formaldehid penambahan formaldehid sangat berpengaruh ikatan aminoplas terdiri dari dua bagian reaksi, yaitu suatu reaksi adisi dan suatu reaksi kondensasi. Secara ringkas, reaksi antara melamin dengan formaldehid ditinjau dari sudut pandang proses polimerisasi dengan karakteristik ikatan $-\mathrm{NH}-\mathrm{CH} 2$, seperti terlihat pada Gambar 3 :<smiles>Nc1nc(N)nc(NCO)n1</smiles>

sehingga lebih mudah bereaksi dan lebih intensif (Bandel 1990; Pizzi ,1991).

\section{Hasil Analisis Viscositas Berdasarkan Perbandingan mol M:F.}

Hasil Analisis Viscositas Berdasarkan Perbandingan mol M:F dapat dilihat seperti Gambar 4.

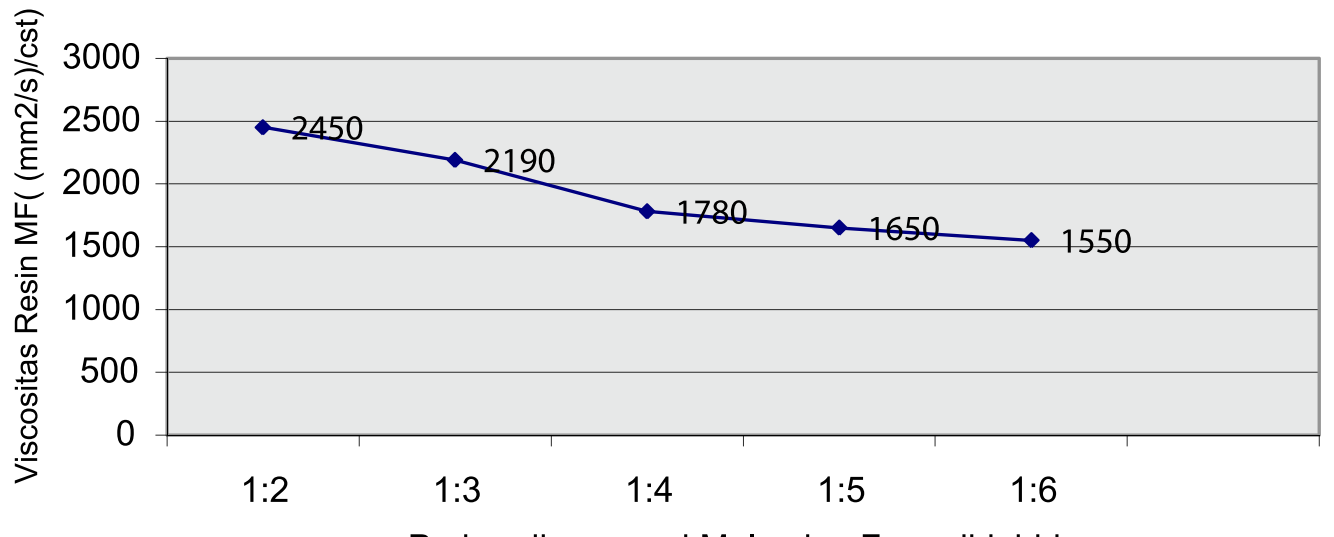

Perbandingan mol Melamin : Formalidehida

Gambar 4. Pengaruh perbandingan mol M:F terhadap viskositas

Berdasarkan gambar 4, menunjukkan bahwa semakin besar mol rasio Melamin:Formaldehida maka viscositas produk resin Melamin Formaldehid yang dihasilkan semakin kecil. Penambahan formaldehida yang semakin besar menyebabkan adanya Formadehida berlebih atau excess yang tidak bereaksi dengan Melamin, kelebihan inilah yang menyebabkan viscositas dari resin MF semakin kecil sehingga kemungkinan terjadinya thermosetting semakin kecil dan pot life lebih lama.

Hasil Analisis Pot Life Berdasarkan Perbandingan mol M:F 
Hasil Analisis Pot Life Berdasarkan Perbandingan mol M:F dapat dilihat seperti gambar 5 .

Semakin besar perbandingan mol M:F maka Pot life (umur pakai) resin yang dihasilkan semakin lama. Hal ini sebagaimana ditunjukkan oleh gambar 5. Seiring dengan semakin kecilnya viscositas maka pot life akan semakin lama. Pot Life yang dihasilkan dari Resin MF ini bisa dikatakan sangat singkat bila dibandingkan dengan resin melamin formaldehid komersial yang dijual dipasaran.

\section{Hasil Analisis pH Berdasarkan Perbandingan mol M:F}

Hasil Analisis $\mathrm{pH}$ Berdasarkan Perbandingan mol M:F dapat dilihat seperti gambar 5 .

Berdasarkan pada gambar 6 dapat dilihat bahwa dengan penambahan formaldehida, nilai $\mathrm{pH}$ semakin kecil (menurun), baik sebelum terjadi reaksi maupun setelah terjadinya reaksi (pemanasan). Secara keseluruhan dikatakan bahwa setelah proses reaksi dengan pemanasan nilai $\mathrm{pH}$ turun.

Hal ini dapat dilihat dari nilai $\mathrm{pH}$ resin melamin formaldehid hampir mendekati netral dan lebih tinggi dari pada coating komersial sehingga lebih ramah lingkungan. Produk komersial IMPRA (resin melamin ) memiliki nilai $\mathrm{pH}$ sekitar 5 dan hardener IMPRA $\mathrm{pH}$ sekitar 1 dan thiner $\mathrm{pH}$ 5. Selain itu melamin memiliki kelarutan dalam air lebih rendah dibandingkan urea, maka tahap hidrofilik berjalan lebih cepat dalam pembentukan resin melamin. Oleh karena intermediate hidrofobik dari kondensasi melamin formaldehid terbentuk lebih awal dalam reaksi (Pizzi,1991), dimana pada fase ini ditunjukkan dengan berubahnya warna resin melamin formaldehid dari bening (tidak berwarna) menjadi putih.

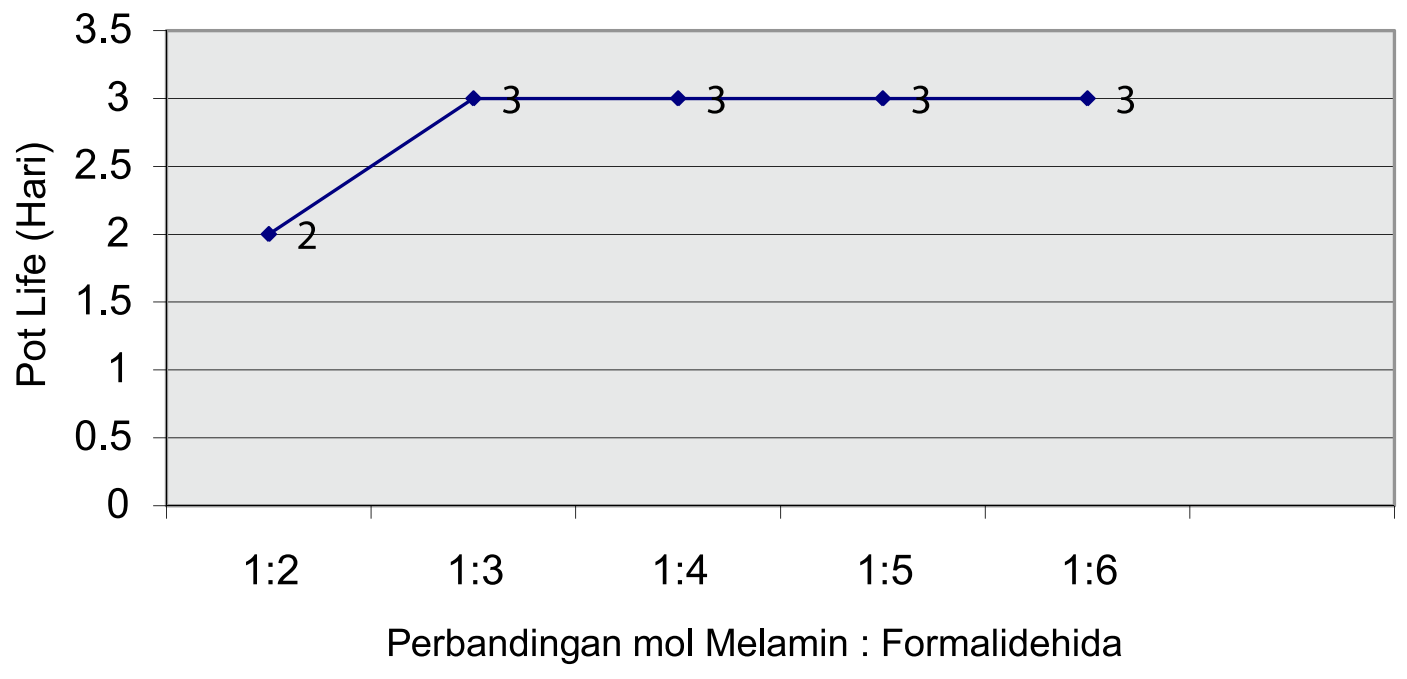

Gambar 5. Pengaruh perbandingan mol M:F terhadap Pot Life 


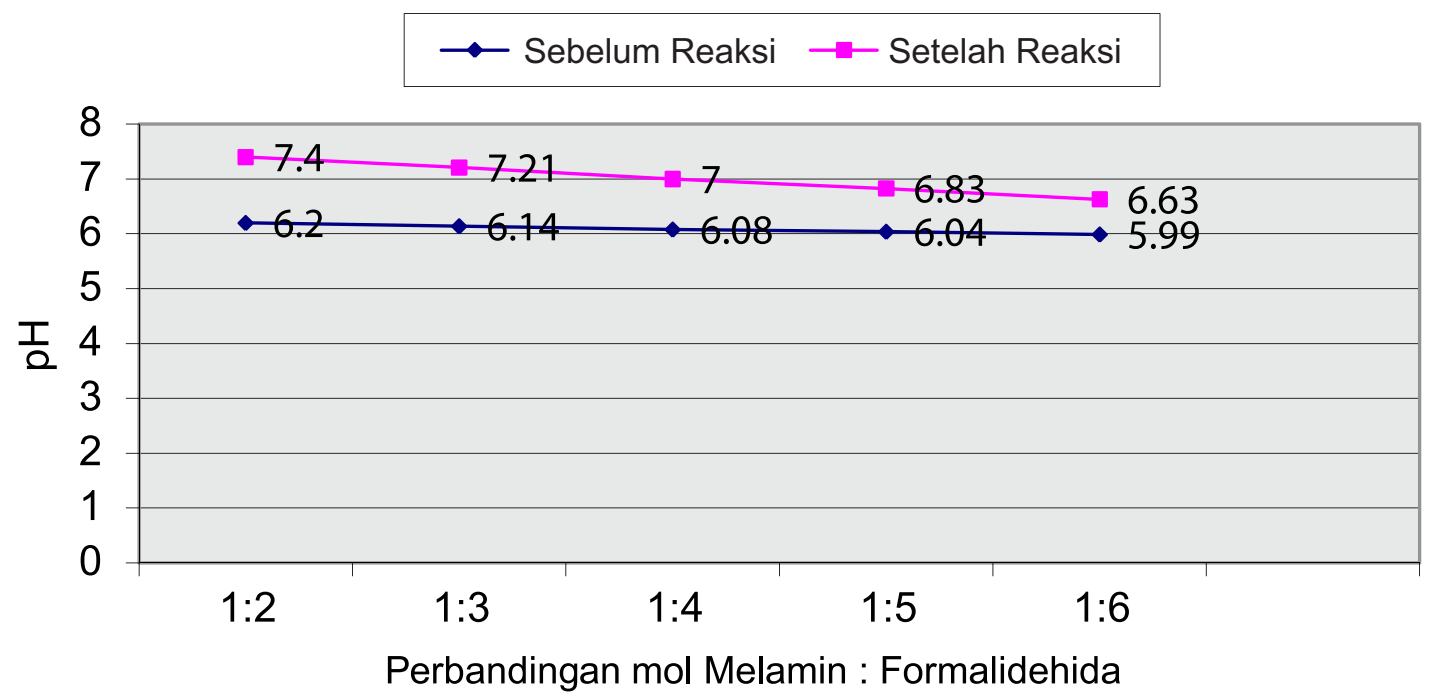

Gambar 6. Pengaruh perbandingan mol M:F terhadap $\mathrm{pH}$

Berdasarkan pada gambar 6 dapat dilihat bahwa dengan penambahan formaldehida, nilai $\mathrm{pH}$ semakin kecil (menurun), baik sebelum terjadi reaksi maupun setelah terjadinya reaksi (pemanasan). Secara keseluruhan dikatakan bahwa setelah proses reaksi dengan pemanasan nilai $\mathrm{pH}$ turun.

Hal ini dapat dilihat dari nilai $\mathrm{pH}$ resin melamin formaldehid hampir mendekati netral dan lebih tinggi dari pada coating komersial sehingga lebih ramah lingkungan. Produk komersial IMPRA (resin melamin ) memiliki nilai $\mathrm{pH}$ sekitar 5 dan hardener IMPRA $\mathrm{pH}$ sekitar 1 dan thiner $\mathrm{pH}$ 5. Selain itu melamin memiliki kelarutan dalam air lebih rendah dibandingkan urea, maka tahap hidrofilik berjalan lebih cepat dalam pembentukan resin melamin. Oleh karena intermediate hidrofobik dari kondensasi melamin formaldehid terbentuk lebih awal dalam reaksi (Pizzi,1991), dimana pada fase ini ditunjukkan dengan berubahnya warna resin melamin formaldehid dari bening (tidak berwarna) menjadi putih.

\section{KESIMPULAN}

Dari hasil penelitian, diperoleh kesimpulan bahwa Resin Melamin Formaldehida yang terbaik dihasilkan pada perbandingan mol Melamin: Formaldehida 1:6 dengan waktu reaksi 14 menit dan karakteristik sebagai berikut: nilai viskositas $1.550(\mathrm{~mm} 2 / \mathrm{s}) /$ centi stokes; Pot Life 3 hari dan pH 6,63. Untuk aplikasi penelitian lebih lanjut, resin hasil penelitian dapat diaplikasikan pada bahan baku meubel.

\section{DAFTAR PUSTAKA}

Bandel, A., 1990, Gluing Wood, Edited by CATAS, Via Antica San Giavanni, al Natisone Udine.

Baumann, H., 1967, Leime und Kontaktkleber: Theoretische Grundlagen, Eigenschaften, anwendung, Springer-Verlag, Berlin, New York.

Habenicht, G., 1997, Kleben: Grundlagen, Technologie, Anwendung, Springer-Verlag, Berlin.

Pizzi, A., 1991, Tanni-Based Adhesive, J. Macromal Sc. Rev. Macromol, Chem. And Tech. Vol. 2.

Roffael, E., 1975, Messung Der Formaldehydabgabe : Praxisnahe Methoden zur Ermittlung der Form a I d e h y d a b g a b e harnstoffharzgebundener Spanplatten fur das Bauwesen, Holz-Zentralblaat 101: 1403-1404.

Rosamah, E., 2004, Einige Aspekte der Tanninverleimung CUVILLIER VERLAG, Gottingen.

SNI, 1998, "Kumpulan SNI Perekat, Badan Standardisasi Nasional, Jakarta. 